\title{
On the use of EBSD analysis to investigate the microstructure of gold samples built by selective laser melting
}

\author{
Jamasp Jhabvala $\cdot$ Eric Boillat · Rémy Glardon
}

Published online: 15 June 2011

(C) The Author(s) 2011. This article is published with open access at Springerlink.com

\begin{abstract}
In the selective laser melting process, the scanning strategies have a deep impact on the final microstructures. In this paper, we point out the benefits of using EBSD techniques to characterize the scanning strategies on 18-carat gold samples. For a given scanning strategy, different microstructures and orientation can be achieved, due to the change of the thermal gradients. The results are compared with numerical simulations.
\end{abstract}

Keywords Selective laser melting process - EBSD • Scanning strategy $\cdot$ Thermal gradients $\cdot$ Numerical simulations

\section{Introduction}

Selective laser melting (SLM) is an additive manufacturing technique, formerly called selective laser sintering (SLS). It was developed and patented by Dr. Deckard from the University of Texas at Austin in 1986. During the process, the object is built layer by layer. A laser source is responsible for the consolidation, by local heating. The light is deviated by a scanning head according to the instructions of an STL file. Then fusion of the particles takes place, followed by a solidification of the liquid created. Kinetics of these

J. Jhabvala $(\varangle) \cdot$ E. Boillat $\cdot$ R. Glardon

Laboratoire de Gestion et Procédés de Production,

IGM-STI, Station 9, Ecole Polytechnique Fédérale de

Lausanne (EPFL), 1015 Lausanne, Switzerland

e-mail: jamasp.jhabvala@epfl.ch steps are very high and play an important role in the final microstructure (rearrangement of the particles, pore creation, residual stresses).

In SLM, the particles are completely molten under the laser beam and form a liquid bath. This is not the case for SLS where only a partial fusion of the particles is observed. The transition from SLS to SLM was driven by the need to produce near fully dense objects, with mechanical properties comparable to those of bulk materials and by the desire to avoid post-processing cycles. But due to the difficulty to find process windows, the range of commercially available SLM metals is limited today [1]. The powder can be a single-material powder, an alloyed material powder, or a mixture of powders. This technique is already widely used in different fields such as aerospace, machinery, medical and dental applications, art, and jewelry [2].

In SLS, the main parameters are the laser power, the pulse frequency, and the scan speed. The scanning strategy is of less importance. In SLM, the goal is to completely melt the powder in order to have dense parts. Consequently, a very high laser power is used and the negative thermal effects, like thermal stresses [3] or balling effects [4], are important. When dealing with gold, these effects are often of importance due to its excellent thermal conductivity. A solution to control this problem is to adjust the scanning strategy.

In most cases, balling effects can be due to Marangoni convection related to inhomogeneous temperature distributions [5]. In the same way, thermal stresses are related to thermal gradients [6]. The main idea to avoid most of the negative thermal effects is to reproduce the thermal conditions governing classic sintering. In an oven, the whole part is heated smoothly and the temperature gradients are always very low. 
Our goal is to present how electron backscattered diffraction (EBSD) experiments can help to distinguish between favorable and unfavorable scanning strategies and to link the results to numerical simulations.

\section{State of the art}

Selective laser melting of gold

The use of selective laser melting in jewelry or watchmaking is of great interest. It allows the manufacture of complex shapes that cannot be produced by conventional techniques. Furthermore, expensive molds and dies are no longer needed when dealing with small series, and all the unused powder can be reused without a recycling step (as for chips, for example). However, very little work has been published on the laser melting of precious metals like gold and its alloys. In [7], selective laser melting is used on a 24-carat gold powder, and a process window is found.

\section{Scanning strategies}

Scanning strategies are poorly reviewed in the literature. In [8], a model is proposed for calculating the evolution of temperature and thermal stresses within a single metallic layer on a powder bed using different scanning patterns. They conclude that the best scanning strategy is based on fractals. In [9], a three-dimensional FE model is developed to identify the heat impact on deformations and residual stresses, according to different scanning strategies. In [10], the influence of the scanning strategy on the microstructure of a $\mathrm{Ti}-$ $6 \mathrm{Al}-4 \mathrm{~V}$ alloy is studied and show the occurrence of epitaxial growth.

\section{Electron backscattered diffraction}

If a material is crystalline, the backscattered electrons can be diffracted by the lattice, following Bragg's law [11]. To collect this information, a diffraction camera must be mounted in the SEM. It consists of a phosphor screen and a CCD camera to register the image on the screen. The sample has to be flat and polished. It is tilted $\left(\sim 70^{\circ}\right.$ from horizontal) towards the diffraction camera. Each crystallographic plane corresponds to two parallel lines on the screen, called Kikuchi lines, and the distance between these lines is related to the Bragg angle. A diffraction figure is drawn for each scanned point, consisting of intersecting Kikuchi lines. Then, a software identifies automatically the crystallographic structure and the orientation of each zone.

\section{Numerical model}

The simple linear heat equation fails to describe properly the laser-matter interactions and the temperature evolution inside the scanned powder bed. The reason is that the latent heat of material and the modification of its conductivity $k$ during sintering play an important role and have to be taken into account [12-15]. The model to be used is an evolution equation for the specific enthalpy $u$ (Stefan-problem [16]):

$\rho \partial_{t} u-\operatorname{div} k \operatorname{grad} T=0$

coupled with a state equation binding $u$ and the temperature $T$ :

$T=\beta(u)$

The nonlinear functions $\beta$ involves the specific heat $C_{\mathrm{p}}$, the latent heat $L$ as well as the fusion temperature $T_{\mathrm{f}}$. A typical choice for the function $T=\beta(u)$ is schematically given in Fig. 1.

In Eq. 1, $\rho$ represents the density. Since there is no macroscopic velocity in the material, $\rho$ cannot depend on time because of mass conservation [12]. In SLS, a slow microscopic shrinkage actually takes place but the time dependency of the density can be neglected in Eq. 1. To allow for conductivity modification during sintering, we use a Frenkel-type law [12, 17]:

$\partial_{t} k=a\left(k_{\text {bulk }}-k\right)$

where $k_{\text {bulk }}$ is the conductivity of the corresponding bulk material. The coefficient $a$ has a dimension of

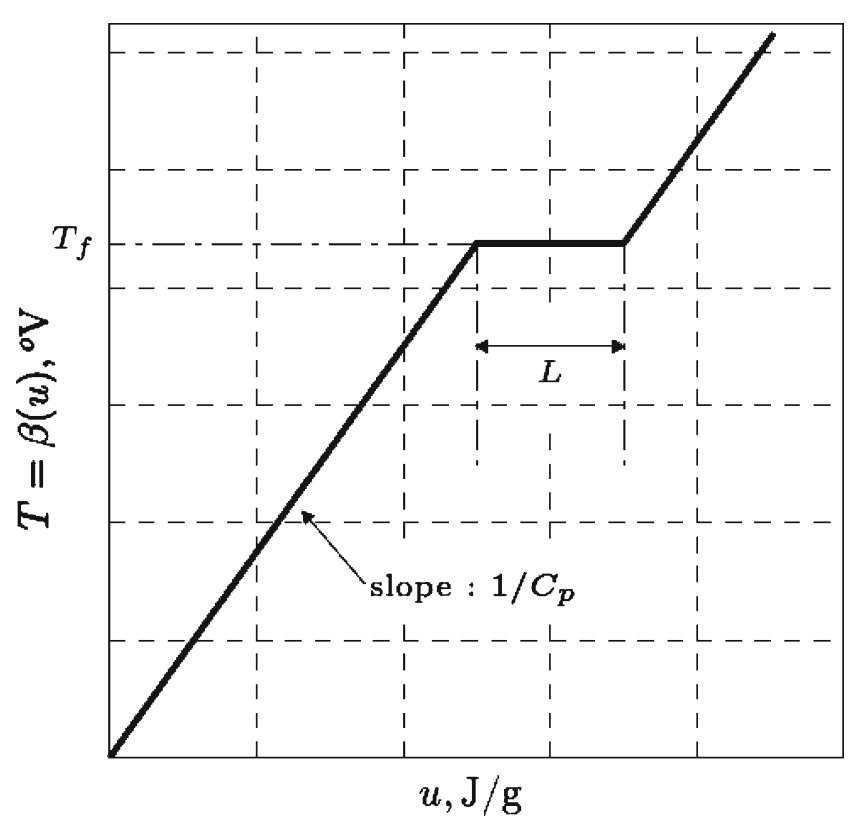

Fig. 1 Typical choice for the function $T=\beta(u)$ 
Table 1 Thermal properties of gold

\begin{tabular}{llll}
\hline & Bulk & Powder & Unit \\
\hline Surface absorption $\alpha_{\mathrm{s}}{ }^{\mathrm{a}}$ & 0.885 & 17.7 & $\%$ \\
Density $\rho$ & 19.32 & 12.56 & $\mathrm{~g} / \mathrm{cm}^{3}$ \\
Specific heat $C_{\mathrm{p}}$ & 0.1323 & & $\mathrm{~J} / \mathrm{g}^{\circ} \mathrm{C}$ \\
Thermal conductivity $k$ & 301 & 3.01 & $\mathrm{~W} / \mathrm{m}^{\circ} \mathrm{C}$ \\
Melting temperature $T_{\mathrm{m}}$ & $1,064.4$ & & ${ }^{\circ} \mathrm{C}$ \\
Latent heat of fusion $L$ & 66.2 & & $\mathrm{~J} / \mathrm{g}$ \\
\hline
\end{tabular}

${ }^{\mathrm{a}}$ For a $\mathrm{Nd} / \mathrm{YAG}$ laser, normal incidence

$1 / \mathrm{s}$ and is temperature dependent (usually, $a=0$ if the temperature is below a given sintering threshold). The laser activity is taken into account as a surface heat source through the boundary condition for pde (Eq. 1). Since the laser spot is very small compared with the dimension of the powder bed (both scales typically differs by a factor $>1,000$ ), nonconformal FEM grids [18] are used to solve the problem. The thermal characteristics of the material to be used in the simulation are listed in Table 1.

\section{Experimental setup}

The SLM platform

The laser is a Nd/YAG (Quantronix Condor) operating with an average power of $100 \mathrm{~W}$. In normal mode (multimode), the focal beam radius is $\sim 150 \mu \mathrm{m}\left(M^{2}=\right.$ 13). The deposition chamber is made of stainless steel. A vacuum pump permits to reach $5 \cdot 10^{-2}$ mbar. Argon is then injected inside to avoid possible reactions with the atmosphere.

The powder

The powder to be consolidated is a basic 18-carat yellow gold powder (see Fig. 2). Its composition is 75 wt. $\%$ gold, $12.5 \%$ silver, and $12.5 \%$ copper. It is gas atomized, spherical, and distributed around $10 \mu \mathrm{m}$ (monomodal). It contains no minor alloying additions such as zinc, which vapourises easily and could affect the process. It is also well suited for SLM because of its high thermal conductivity and diffusivity. Experiments with a low-conductive powder (tungsten carbide coated with stainless steel [19]) have been carried out in [20].

\section{EBSD analysis}

Samples for EBSD are embedded in a conductive resin (Konductomet from Buehler) and polished with diamond paste down to $0.25 \mu \mathrm{m}$. A chemical attack is nec-

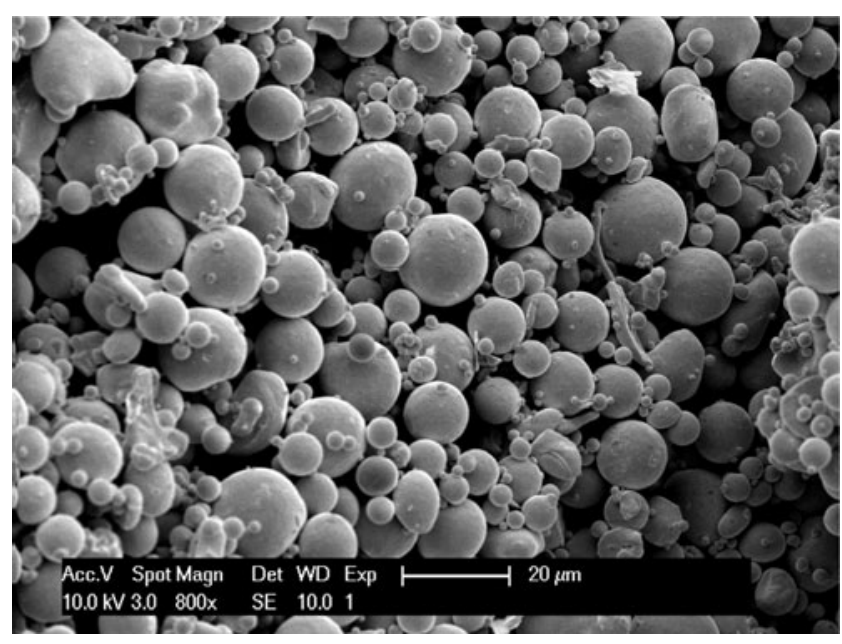

Fig. 2 The 18-carat gold powder (75 wt. \% gold, $12.5 \%$ silver, and $12.5 \%$ copper). It is gas atomized and distributed around $10 \mu \mathrm{m}$

essary to remove the hardened layer at the surface of the sample. It consists of successive bufferings of $\mathrm{NaCN}$ $(10 \mathrm{~g} / 100 \mathrm{ml}$ water $)$ and $30 \%$ oxygenated water [21].

\section{Results}

The scanning strategy investigated here is the parallel scanning (see Fig. 3).

It has the advantage of being the easiest to generate from a CAD file. Three other strategies have been investigated in [20].

The hatching distance $h_{\mathrm{d}}$ is set to be $h=50 \mu \mathrm{m}$. Only the power $P$ and the scan speed $v$ are variable and adapted to the material.

At low speed, the parallel scanning strategy leads to large temperature gradients all over the square surface to be consolidated which is an unfavorable situation.

Simulation results show that a feasible solution to decrease temperature gradients is to use higher scan speed $v$. By letting $v \rightarrow \infty$, we tend to homogeneous energy deposition (see "State of the art"). However, the highest scan speed one can use depends on the scan

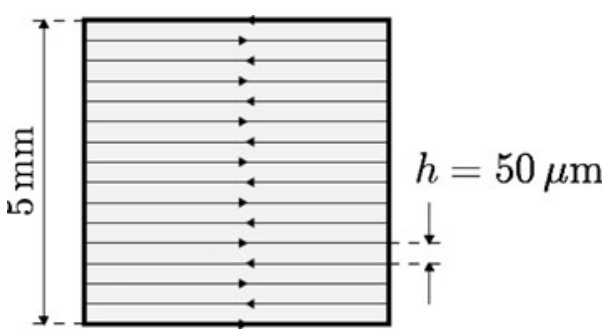

Fig. 3 The parallel scanning strategy 


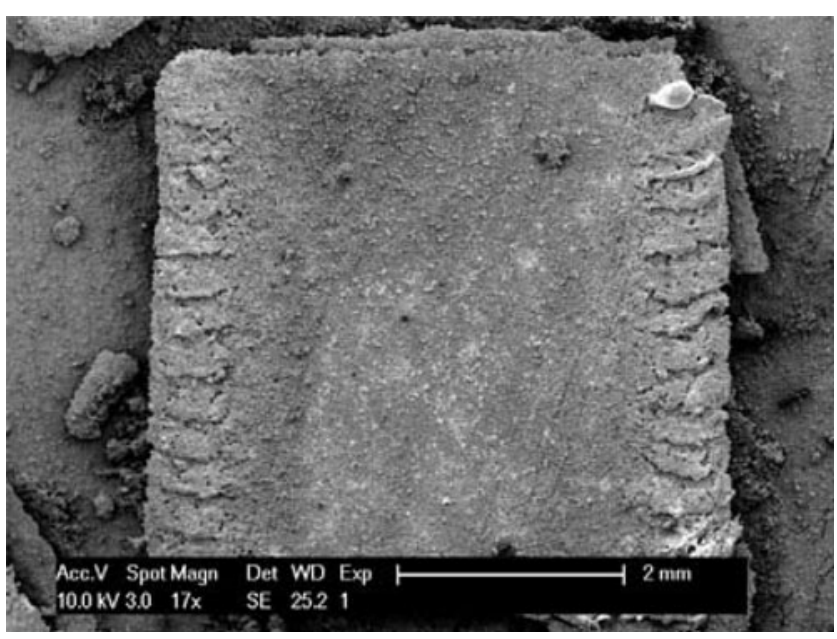

Fig. 4 The parallel scanning leads to balling and cracks on the two borders that are perpendicular to the scanning direction

head capability. Moreover, to avoid depositing less and less energy, the power has to be increased in the same proportion as $v$. Since laser powers are usually limited to a few hundreds watts, a way to increase $v$ without depositing less and less energy is the so-called multiple scanning strategy: the speed $v$ is multiplied by an integer $n(n=2,3 \ldots)$, the power is not modified but the laser beam goes through the scanning path not once but $n$ times.

However, even at high speed and reasonable power, the parallel scanning leads to balling and cracks on the two borders that are perpendicular to the scanning direction (see Fig. 4).

Figure 5 shows an EBSD analysis of one of these border. Each color corresponds to a different crystallographic orientation. There are clearly two different groups of grains. At the border, columnar grains can be seen, following the thermal gradients. At a certain distance from the border, a transition occurs and equiaxed grains appear, with no preferential growth direction.

A simulation of the above experiment has been performed with the model described in "Numerical model". On Fig. 6, we plot the maximal temperature profiles after one scan in the horizontal direction (parallel to the scanning path) and the vertical direction (perpendicular to the scanning path). The horizontal profile shows a temperature rise near the borders of the sample and this effect increases with the following scans. Because the temperature reaches higher values, the liquid lifetime is longer. A part of the previously solidified grains can be remelted. Therefore, the solidifying material keeps the same crystallographic orientation. Grains oriented towards the thermal gradient
Fig. 5 EBSD analysis of a parallel scanning with two different groups of grains. At the border, columnar grains can be seen, following the thermal gradients. At a certain distance from the border, a transition occurs and equiaxed grains appear, with no preferential growth direction

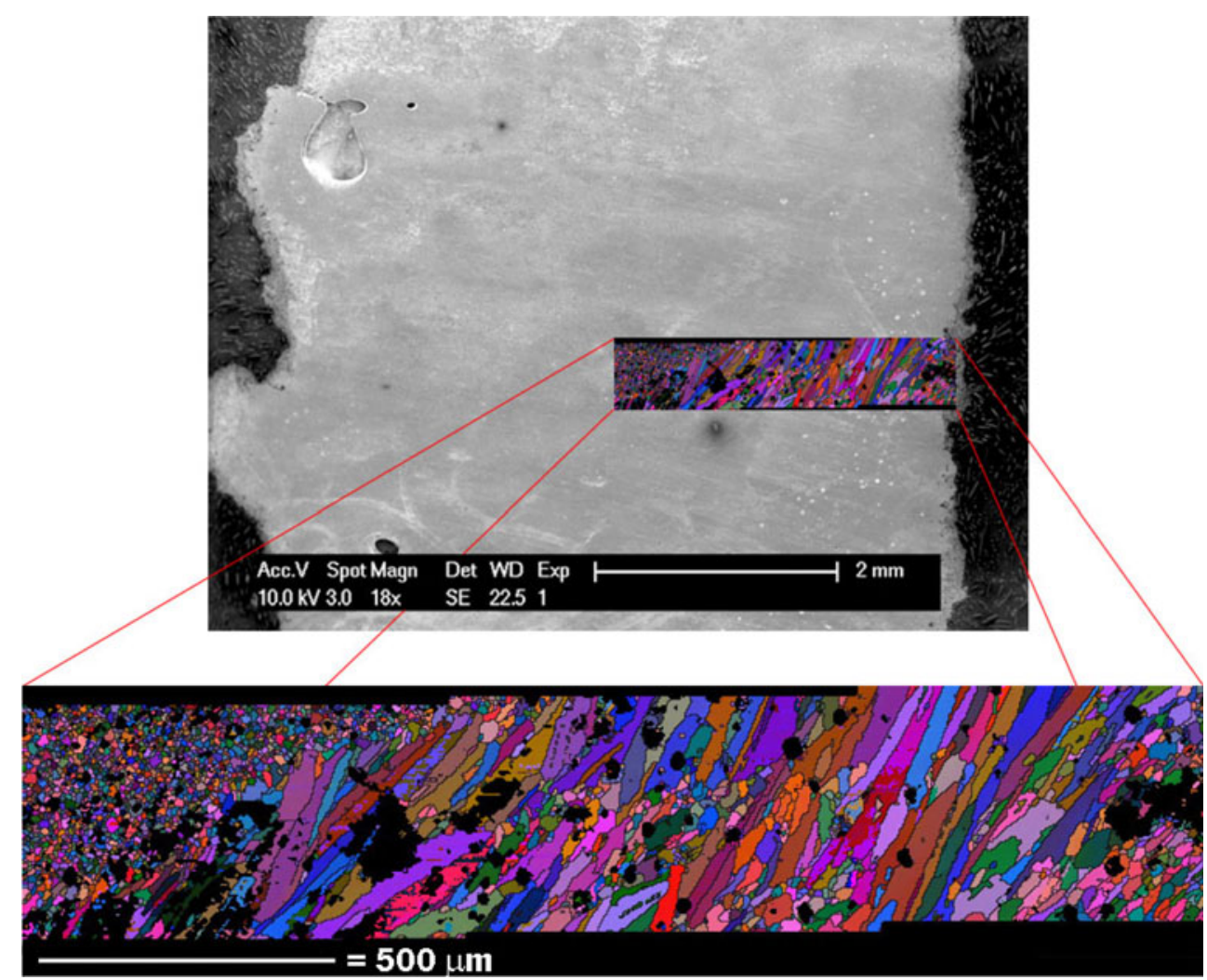




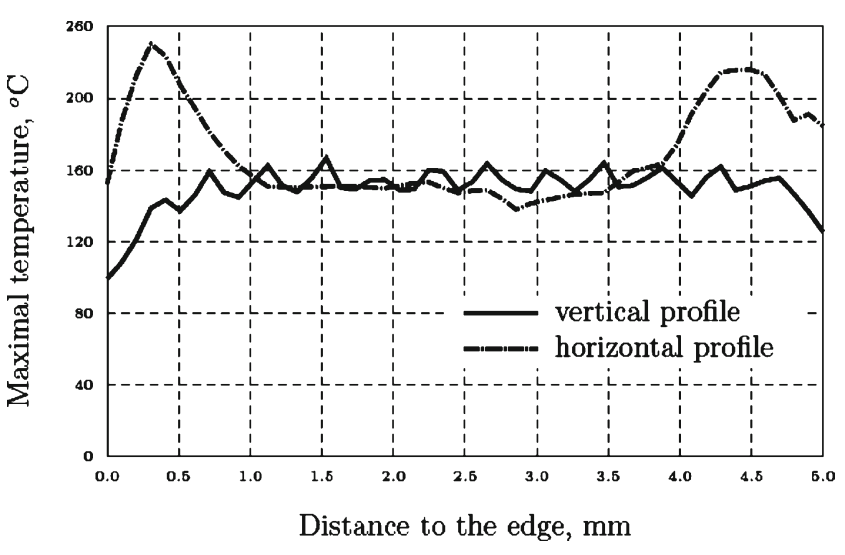

Fig. 6 The maximal temperature profile in the horizontal direction (parallel to the scanning path) after one scan shows a temperature rise near the borders of the sample

grow preferentially, as studied in [22]. The same result for Ti-6Al-4V parts made by SLM has been found in [10]. On the contrary, at the center the grains have only time to nucleate before the metal cools down.

In general equiaxed grains, which lead to an isotropy of the mechanical properties, are preferable. So, it appears that the columnar grains have to be avoided and scanning strategies favorable to equiaxed grains should be chosen.

A vertical cross section of a piece made with the same powder has been analyzed via EBSD (see Fig. 7). The layers are $50 \mu \mathrm{m}$ high. The black parts on the EBSD picture are not necessarily pores but parts where the EBSD software could not find any crystallographic informations, maybe due to the presence of resin. There are no cracks apparent between the layers, and the
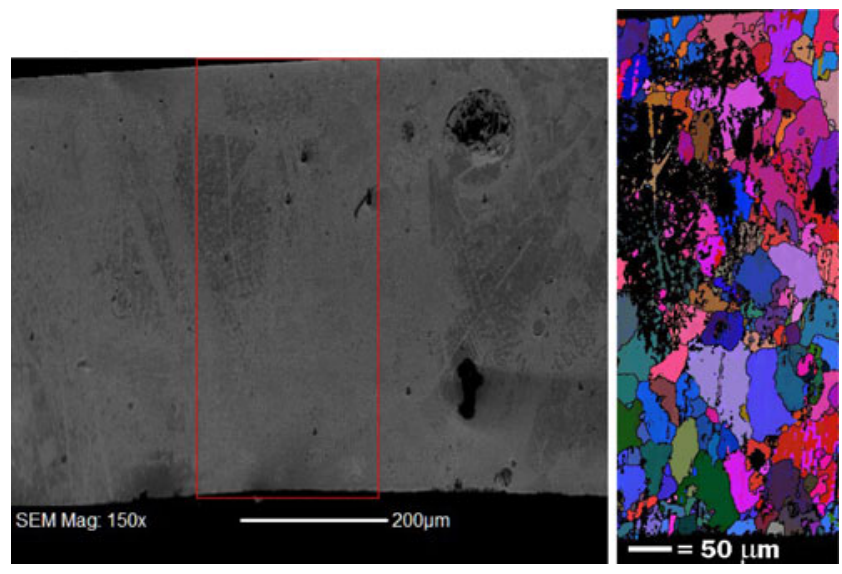

Fig. 7 EBSD analysis through different layers. When a layer is irradiated, the metal of the previous layer is partially remelted, and the previous crystallographic orientations is kept. This ensures a good bonding between the layers, and good mechanical properties can be expected
Fig. 8 The paintbrush scanning strategy

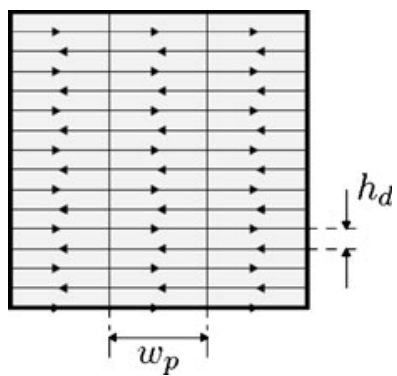

grains have grown sometimes through two or three layers. When a layer is irradiated, the metal of the previous layer is partially remelted, and the previous crystallographic orientations is kept. This ensures a good bonding between the layers, and good mechanical properties can be expected.

These results show that EBSD analyses combined with numerical simulations are a powerful tool for choosing the best scanning strategies in order to get limited grain growth, isotropic material and good mechanical properties.

\section{Conclusions}

We have shown that the parallel scanning strategy has some drawbacks when using a conductive powder such as 18-carat gold. An interesting alternative is to scale down the parallel scanning and to go to the so-called paintbrush (or stripe) scanning (see Fig. 8).

Since the areas to consolidate are smaller, the temperature homogeneity is easier to maintain [20]. EBSD analysis show the benefits one can obtain from avoiding thermal gradients.

An important output of this paper is that using the numerical model described in "Numerical model" is an inexpensive and efficient way to evaluate the drawbacks and the benefits of a given scanning strategy. It is able to detect overheated zones or high temperature gradients. In the future, it could be combined to selection algorithms to form a computer-based tool for generating adapted scanning strategies.

Acknowledgments We are thankful to the Interdisciplinary Centre for Electron Microscopy (EPFL) for giving us access to electron microscopes and to Emmanuelle Boehm-Courjault and Alain Jacot at LSMX (EPFL) for the help with EBSD experiments and many fruitful discussions.

Open Access This article is distributed under the terms of the Creative Commons Attribution License which permits any use, distribution, and reproduction in any medium, provided the original author(s) and source are credited. 


\section{References}

1. Kruth JP, Mercelis P, Froyen L, Rombouts M (2004) Binding mechanisms in selective laser sintering and selective laser melting. In: Bourell DL, Beaman JJ, Crawford RH, Marcus HL, Barlow JW (eds) Proceedings of the 10th solid freeform fabrication symposium, Austin, Texas

2. Wohlers T (2010) Wohlers report 2010. Wohlers Associates, Fort Collins

3. Pohl H, Simchi A, Issa M, Dias HC (2001) Thermal stresses in direct metal laser sintering. In: Bourell DL, et al. (eds) Solid freeform fabrication symposium proceedings, vol 12, pp 366372

4. Tolochko NK, Mozzharov SE, Yadroitsev IA, Laoui T, Froyen L, Titov VI, Ignatiev MB (2004) Balling processes during selective laser treatment of powders. Rapid Prototyping J 10(2):78-87

5. Rombouts M, Kruth JP, Froyen L, Mercelis P (2006) Fundamentals of selective laser melting of alloyed steel powders. CIRP Ann Manu Tech 55(1):187-192

6. Mercelis P, Kruth JP (2006) Residual stresses in selective laser sintering and selective laser melting. Rapid Prototyping J 12(5):254-265

7. Khan M, Dickens P (2010) Selective laser melting (slm) of pure gold. Gold Bull 43(2):114

8. Ma L, Bin H (2007) Temperature and stress analysis and simulation in fractal scanning-based laser sintering. Int $\mathrm{J}$ Adv Manuf Technol 34(9):898-903. doi:10.1007/s00170-006-0665-5

9. Zaeh MF, Branner G, Krol TA (2009) A three dimensional fe-model for the investigation of transient physical effects in selective laser melting. In: Bártolo PJ, et al. (eds) Innovative developments in design and manufacturing, advanced research in virtual and rapid prototyping. Taylor \& Francis, New York

10. Thijs L, Verhaeghe F, Craeghs T, Van Humbeeck J, Kruth J-P (2010) A study of the microstructural evolution during selective laser melting of ti-6al-4v. Acta Mater 58(9):33033312

11. Schwartz AJ, Kumar M, Adams BL (2000) Electron backscatter diffraction in materials science. Kluwer, Norwell

12. Kolossov S (2005) Non-linear model and finite element simulation of the selective laser sintering process. Ph.D. thesis, EPFL 3178

13. Fischer P, Leber H, Romano V, Weber HP, Karapatis N, André C, Glardon R (2003) Microstructure of near infrared pulsed laser sintered Titanium samples. Appl Phys A 78(8)1219-1227 (published online)

14. Gusarov AV, Kruth JP (2003) Mathematical simulation of radiation transfer in the powder bed: application to selective laser sintering. In: Lallement G, Lexcellent C, Perreux D, et al. (eds) Proceedings of the $1^{\text {st }}$ int. conf. on advanced research in virtual and rapid prototyoping, journal de physique IV, vol 12. EDP Science

15. Gusarov AV, Laoui T, Froyen L, Titov VI (2003) Contact thermal conductivity of a powder bed in selective laser sintering. Int J Heat Mass Transfer 46:1103-1109

16. Meyer GH (1973) Multidimensional Stefan problems. SIAM J Numer Anal 10:522-538

17. Frenkel J (1945) Viscous flow of crystalline bodies under the action of surface tension. J Phys USSR 9:385-391

18. Boillat E (2003) Finite element methods on non-conforming grids by penalizing the matching constraint. M2AN 37(2)

19. Fernandes CM, Ferreira VM, Senos AMR, Vieira MT (2003) Stainless steel coatings sputter-deposited on tungsten carbide powder particles. Surf Coat Technol 176:103-108

20. Jhabvala J, Antignac T, Boillat E, Glardon R (2010) On the effect of scanning strategies in the selective laser melting process. Virtual and physical prototyping 5(2):99-109

21. Favez D (2009) Soudage laser or-acier: métallurgie et procédé. Ph.D. thesis EPFL, 4353

22. Rappaz M, Gandin Ch-A, Desbiolles J-L, Thévoz Ph (1996) Prediction of grain structure in various solidification processes. Metall Mater Trans, A 27A 